Pak. J. Agri., Agril. Engg., Vet. Sci., 2020, 36 (1): 78-84

https://doi.org/10.47432/pjaaevs.2020.36.1.11

ISSN: 1023-1072 (Print), ISSN: 2663-7863 (Online)

\title{
PREPARATION AND COMPARATIVE EVALUATION OF HAEMORRHAGIC SEPTICAEMIA VACCINES USING EOLANE-150 AND EOLANE-170 AS OIL ADJUVANTS FOR CATTLE AND BUFFALO
}

\author{
W. Shahzad ${ }^{1 *}$, B. Zameer, S. H. Sanghi, S. Hussain and N. Mustafa \\ ${ }^{1}$ Veterinary Research Institute, Lahore Cantt, Pakistan
}

\begin{abstract}
Haemorrhagic septicaemia (HS) caused by Pasteurella multocida serotype B:2 is an economically important disease of cattle and buffalo, causes heavy economic losses due to sudden death of animals in developing countries like Pakistan. In this country, animals are vaccinated by alum (adjuvant) precipitated vaccine twice a year. Immunity induced through this prophylactic measure lasts for 3-4 months only. Two new HS oil based vaccines were prepared by using two new oil adjuvants such as Eolane-150 and Eolane-170. The ratio of bacterial antigen and oil adjuvants was 1:1 while bacterial dry weight was adjusted to $2 \mathrm{mg} / \mathrm{ml}$. The addition of enrichments and aeration resulted in dense bacterial growth of Pasteurella multocida. Both new vaccines passed sterility, safety and potency tests as per OIE, 2017. Active and passive Mouse Protection Tests were performed to evaluate its potency. Indirect Haem-Agglutination (IHA) test was conducted on serum samples of two rabbits, groups each of which was vaccinated with HS oil based vaccines adjuvanted with Eolane-150 and Eolane-170. IHA indicated that immune response was higher (GMT $=32$ ) initially on $45^{\text {th }}$ day to $75^{\text {th }}$ day post vaccination and then declined $(G M T=16)$ in the rabbits vaccinated with HS vaccine adjuvanted with Eolane-150, while protective immune response remained constant $(G M T=16)$ up to ninety days post vaccination in the rabbits vaccinated with HS vaccine adjuvanted with Eolane-170. Vaccines were easy to inject with no side effects, including swelling at the injection site and longer protection as well. That would hopefully motivate the livestock owners and farmers to use this new product to protect their animals against this fatal HS disease.
\end{abstract}

Keywords: active mouse protection test, haemorrhagic septicaemia, iha, oil adjuvant vaccine, passive mouse protection test

\section{INTRODUCTION}

Haemorrhagic septicaemia (HS) caused by Pasteurella multocida serotype $\mathrm{B}: 2$ is a highly fatal and economically devastating bacterial disease of cattle and water buffalo in Asia, Africa and Middle East with highest incidence in South East Asia (Shahzad et al., 2013; OIE, 2018). Different studies indicated that Pasteurella multocidaserotype B:2 causes high mortality (upto 50\%) in several parts of Pakistan (Khan et al., 2011). The disease is more prevalent with highest mortality in buffalo calves of age 6-12 months (Farooq et al., 2011). The disease is seasonal in its occurrence (Tariq et al., 1997). The environment (high ambient temperature), management (overcrowding, inadequate ventilation and transportation) and malnutrition are among the plausible factors which are incriminated to potentiate the incidence of $\mathrm{HS}$ disease in Pakistan (Tariq et al., 1997).

*Corresponding author: waseem1971@hotmail.com
Acute nature and short duration of the disease are main causes of therapeutic failure in affected animals. The disease can only be controlled through mass vaccination programme. Different types of vaccines for HS disease are being prepared such as bacterin, alum and aluminium hydroxide gel based vaccine and oil adjuvanted vaccine. Bacterins are readily absorbed from the site of inoculation and immunity is of limited duration. While alum and aluminium hydroxide gel based vaccines give the immunity only for 3-4 months. Oil adjuvanted vaccine has advantage over alum precipitated vaccine because former confers immunity for one year. In past, oil adjuvanted vaccine prepared from liquid paraffin and lanoline was being used. The vaccine prepared thus gave the immunity for one year (Bain et al., 1982; Jaffri et al., 2006; Kumar et al., 2011) but having dis-advantages of possessing high viscosity (difficult to inject), high dose rate (5cc) and swelling at injection site. Montanide ISA-50 
V2 is a ready to use oil adjuvant and has been proved for preparation of a user friendly, thinner emulsion/vaccine (Aucouturier et al., 2001; Afrooz et al., 2016). Eolane-150 and Eolane-170 (TOTAL, PARCO, Pakistan) are new generation of mineral oils which are being used as adjuvant for preparation of veterinary vaccines in almost all parts of the world. Keeping in view the advantages of Eolane-150 and Eolane-170 (cost effective, user friend and cheap) the present study was conducted to prepare oil based HS vaccine by using these adjuvants and to evaluate their efficacies in lab animals.

\section{MATERIALS AND METHODS Activation of Pasteurella multocida seed}

Freeze dried seed of Pasteurella multocida serotype B:2 was reconstituted with nutrient broth and incubated at $37^{\circ} \mathrm{C}$ for $4-5 \mathrm{hrs}$. The reconstituted seed was injected sub-cutaneously in Swiss Albino mice. Immediately after the death of mice, postmortem was conducted and heart blood was collected aseptically, cultured on Brain Heart Infusion (BHI) broth and incubated at $37^{\circ} \mathrm{C}$ for $24 \mathrm{hrs}$. Heart blood was also cultured on nutrient, Mac-Conkey's and Sabouraud's agar slants and thioglycolate media to check the purity of the seed. After clearing the purity microscopically as well as on the basis of growth characteristics, the cultured seed in $\mathrm{BHI}$ was stored at $4^{\circ} \mathrm{C}$ (OIE, 2018).

\section{Media preparation and vaccine production} For HS vaccine production BHI broth (Merck, India) was prepared with final $\mathrm{pH} 7.4$. The media was checked for sterility by incubating it at $37^{\circ} \mathrm{C}$ for $24 \mathrm{hrs}$. Enrichments were prepared with following concentrations and sterilization temperatures as shown in Table 1. All enrichments were checked for sterility by incubating at $37^{\circ} \mathrm{C}$ for 24 hours. BHI broth prepared was cultured with the pure seed of $P$. multocida serotype B:2 at the rate of $50 \mathrm{ml}$ per litre of media. The enrichments were transferred aseptically in BHI (OIE, 2018).

\section{Aeration process}

Cultured vessels were provided sterile air by syringe filters $(0.2 \mu \mathrm{m}$ pore size, Maxipore, England) through a compressor using sparging aeration and vortexing technique and air was dispersed through a sparger. The vessels were incubated at $37^{\circ} \mathrm{C}$ for $15-18 \mathrm{hrs}$ on a shaker having to-and-fro motion with $60-80 \mathrm{rpm}$. The purity of flasks was checked microscopically and growth was terminated by the addition of formalin (Merck, Germany) at the rate of $0.5 \%$ final concentration. The formalized cultured media was kept at $37^{\circ} \mathrm{C}$ for $24 \mathrm{hrs}$ after shaking vigorously. The bacterin was checked for sterility on nutrient agar, MacConkey's agar, Sabouraud's agar, Thioglycolate medium and nutrient broth. Dry weight of the formalized culture was calculated as described by Bratbak and Dundas (1984) and adjusted to $2 \mathrm{mg}$ per $\mathrm{ml}$ (OIE, 2018).

\section{Preparation of HS oil adjuvanted vaccine}

Oil adjuvanted vaccines were prepared by emulsification (10000 rpm to $15000 \mathrm{rpm}$ ) using a homogenizer (PAMCO, Pakistan) of equal volumes of Eolane-150 and Eolane-170 oil adjuvants (TOTAL, PARCO, Pakistan) and bacterin. Lanolin was used as emulsifier @ 4\% in Eolane-150 and Eolane-170 oils. Preservative such as Thiomersal (Bio world, USA) was added at the rate of $0.003 \%$ and Formalin (Merck, Germany) was added to a final concentration of $0.5 \%$. Following overnight storage, the mixture was re-emulsified and stored at $4^{\circ} \mathrm{C}$ for 10 days (OIE, 2018).

\section{Stability testing}

Stability test was performed at different storage conditions for oil based vaccines emulsion. The test was performed on samples kept at $4 \pm 0.1^{\circ} \mathrm{C}$ (refrigerator) and $25^{\circ} \mathrm{C} \pm 0.1$ (room temperature) after 24 hours, 14 days and 90 days.

\section{Organoleptic characteristics}

Freshly prepared oil adjuvanted vaccines were investigated organoleptically for colour, liquefaction and phase separation (Bain et al., 1982; Koh et al., 2006; Kumar et al., 2015). Organoleptic characteristics of freshly prepared vaccine were noted after $24 \mathrm{hrs}, 14$ days and 3 months at different storage conditions i.e. refrigerator and room temperature.

\section{Centrifugation test}

Centrifugation test (Koh et al., 2006; Kumar et al., 2015) was performed for the emulsions after 24 hours, 14 days and 90 days.

\section{Drop test}

Drop test as described by Bain et al. (1982); Bomford (1997); Mowat et al. (1997); Aucouturier et al. (2001) was performed for the emulsions after 24 hours, 14 days and 90 days. A drop of each vaccine was poured in a glass beaker of cold water and was checked for stay at the surface. 
Table 1. Details of chemicals used for enrichments for cultivation of $P$. Multocida

\begin{tabular}{|l|l|l|l|l|}
\hline Chemicals & $\begin{array}{l}\text { Quantity in distilled } \\
\text { water } \mathbf{( g / / )}\end{array}$ & $\begin{array}{l}\text { Sterilization } \\
\left.\text { temperature ( }{ }^{\circ} \mathbf{C}\right)\end{array}$ & $\begin{array}{l}\text { Sterilization time } \\
\text { (minutes) }\end{array}$ & Final pH \\
\hline Casein hydrolysate & 2.00 & 107 & 10 & 7.4 \\
\hline Sucrose & 6.00 & 107 & 10 & 7.4 \\
\hline Yeast extract & 6.00 & 107 & 10 & 7.4 \\
\hline Sodium chloride & 5.00 & 121 & 20 & 7.4 \\
\hline $\begin{array}{l}\text { Anhydrous di-potassium } \\
\text { hydrogen orthophosphate }\end{array}$ & 8.60 & 121 & 20 & 7.4 \\
\hline $\begin{array}{l}\text { Anhydrous potassium di- } \\
\text { hydrogen orthophosphate }\end{array}$ & 1.36 & 121 & 20 & 7.4 \\
\hline
\end{tabular}

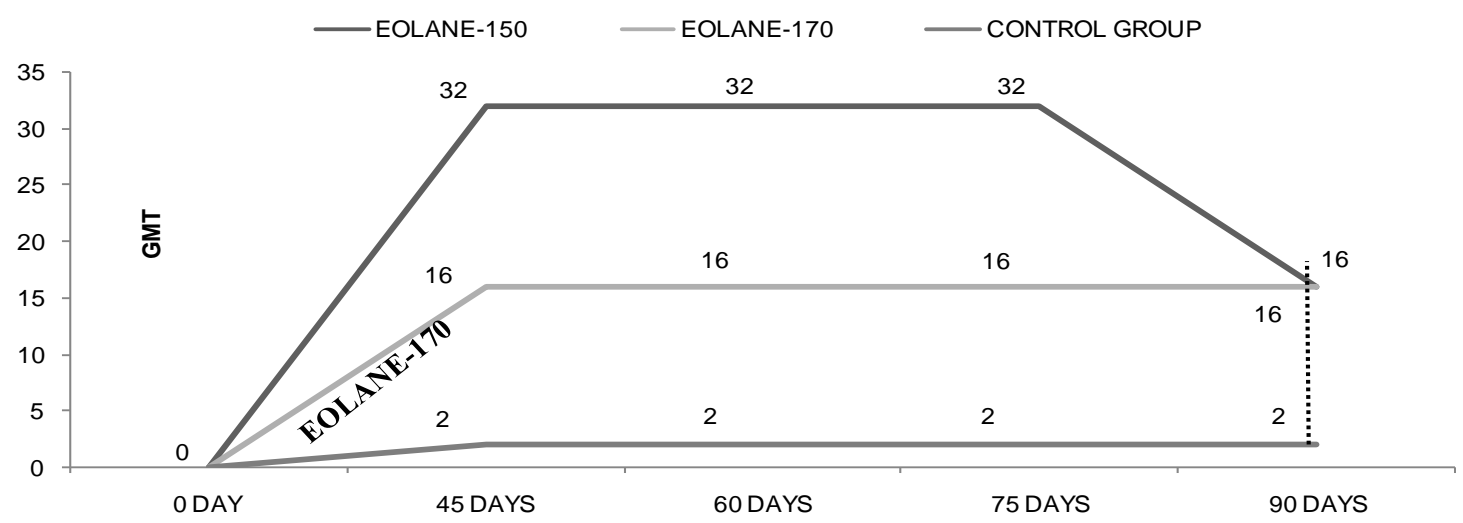

Figure 1. Comparative Geometric Mean Titre of anti-Pasteurella multocida antibodies in rabbits at different days post vaccination of HSOBV with Eolane-150 and Eolan-170 oil adjuvants

\section{Sterility test}

A sample of each prepared vaccine was taken and cultured on nutrient agar, MacConkey agar, Sabouraud's agar, Thioglycolate medium and nutrient broth and incubated at $37^{\circ} \mathrm{C}$ for 7 days (Kumar et al., 2015; OIE, 2018). All the media were daily checked for absence of growth.

\section{Safety test}

A sample of each prepared vaccine was taken and injected (0.2 cc, Intra-muscular) in Swiss Albino mice. All vaccinated mice together with control were observed for five days. Sample was also injected (4cc, deep intramuscular) in two Nili-Ravi Buffalo calves kept at Veterinary Research Institute, Lahore. Vaccinated calves together with control were observed for absence of adverse reactions for 14 days (OIE, 2018).

\section{Potency testing by Active Mouse Protection Test}

AMPT was conducted as described by OIE (2018). Each of 50 Swiss Albino mice was vaccinated intramuscularly with $0.2 \mathrm{ml}$ of each vaccine and again 14 days later for boostering. On day 21, mice were divided into 10 groups consisting of five mice eachand followed by challenge dose of 10 fold dilutions of a 6-8 hours broth culture of $P$. multocida serotype $\mathrm{B}: 2$ in the range of $10^{1}$ to $10^{10}$. Fifty unvaccinated mice were also challenged in the same manner as vaccinated groups. All vaccinated and nonvaccinated mice were observed for 5 days for mortality. Heart blood was checked for the presence of $P$. multocida of the dead mice. $\mathrm{LD}_{50}$ was calculated for vaccinated and nonvaccinated groups by using the method of Reed and Muench (1938). Log of protection was calculated with the difference in the $L_{50}$ of vaccinated and non-vaccinated groups.

\section{Potency testing by Passive Mouse Protection Test}

PMPT was done as described by Bain et al. (1982); Jabbari and Moaeni (2004); Jaffri et al. (2006). To perform this test rabbit serum was used. Ten rabbits were vaccinated $(0.5 \mathrm{ml}$ intramuscularly) with each vaccine at 0 day and 
$2^{\text {nd }}$ vaccination was done on $21^{\text {st }}$ day. Serum samples were collected on day 30 and 45 day after booster. PMPT was done with pooled sera which were obtained from rabbits. The $0.5 \mathrm{ml}$ of the pooled sera was injected in each of 10 mice. The treated mice were divided in two groups 1 and 2. Control group was also divided in two groups; 3 and 4. Fresh 6-8 hours broth culture of $P$. multocida serotype B:2 was prepared for challenge. Groups 1 and 3 were challenged with $100 L_{50}$ and groups 2 and 4 were challenged with $1000 \mathrm{LD}_{50}$ of challenge culture. All the mice were observed daily for 7 days for mortality. Mice that died during the observation period were examined for the presence of bipolar micro-organism in the blood smears and $P$. multocida in blood agar culture media. The results are expressed as the percentage surviving out of 5 after challenge.

\section{Antibody titre estimation in rabbits}

The immune status of each of five rabbits vaccinated with Haemorrhagic Septicaemia Oil Based Vaccine (HSOBV) adjuvanted with Eolane-150 and HSOBV adjuvanted with Eolane-170 (maintained at Veterinary Research Institute, Lahore) was estimated by Indirect Haem-Agglutination (IHA) test. Serum samples were obtained from each group of five rabbits after 90 days post vaccination. IHA test was conducted on these samples as described by Tariq et al. (1997); Bain et al. (1982).

\section{RESULTS}

Both oil based vaccines adjuvanted with Eolane150 and Eolane-170 were found stable upto 90 days at $4^{\circ} \mathrm{C}$ and $25^{\circ} \mathrm{C}$. There was no change in colour, no liquefaction and no phase separation of the both vaccines upto 90 days at $4^{\circ} \mathrm{C}$ and $25^{\circ} \mathrm{C}$. The both vaccines were also found stable after performing centrifugation test upto 90 days. The drop test was cleared for water in oil emulsion upto 90 days. The vaccines were also found sterile and safe as per OIE (2018). In present study, $100 \%$ protection was observed by HS oil based vaccines adjuvanted with Eolane150 and Eolane-170 after challenged at 30 and 45 days post vaccination by $100 \mathrm{LD}_{50}$ and 1000 $\mathrm{LD}_{50}$ in PMPT and a five log protection was obtained in AMPT. The results of IHA conducted on serum samples of two groups of rabbits vaccinated with $\mathrm{HS}$ vaccine adjuvanted with Eolane-150 and Eolane-170 indicated that HS vaccine adjuvanted with Eolane-150 gave initially high level of antibodies titre (GMT=32) from $45^{\text {th }}$ day to $75^{\text {th }}$ day which later on decline
(GMT=16) upto 90 days post vaccination while the other group of rabbits vaccinated with HS vaccine adjuvanted with Eolane-170 gave constant protective antibodies titre $(G M T=16)$ upto 90 days post vaccination (Figure 1 ).

\section{DISCUSSION}

Haemorrhagic Septicaemia (HS) is a seasonal disease of cattle and buffaloes and is controlled by mass vaccination programme before rainy season in Punjab, Pakistan. Immune response to the Bacterin is poor and is of short duration (Tariq et al., 1997). Immune response in vaccinated cattle and buffaloes is required against capsule of $P$. multocida which is composed mainly of lip polysaccharide (LPS) with minor fraction of proteins (Bain et al., 1982). LPS induces $B$ cell response and cannot be presented along with $\mathrm{MHC}$-II antigen by Antigen Presenting Cells (APC) of the animal body, and hence the responsive $B$ cells (plasma cells) cannot get cooperation of $T$ cells for enhanced antibody production. The B cell response to LPS is primary and the immunity is of low level and short duration (Abbas et al., 1991). This property of LPS in Bacterin necessitated the farmers to vaccinate their animals quarterly (Tariq et al., 1997).

The Oil Adjuvanted Vaccine (OAV) work by forming depot of antigen and letting its slow release over long course of time, protect the antigen from rapid degradation by enzymes and recruit the APCs at the injection site and enhances the antigen uptake by these APC (Aucouturier et al., 2001; Aguilar and Rodiguez, 2007). There is a minor fraction of bacterial proteins in the capsule, immunity against which can be potentiated by having it in required level in the dose and adding adjuvants in the Bacterin. In the present study, use of enrichments media and provision of fresh filtered air during incubation resulted $2 \mathrm{mg}$ bacterial dry weight per $\mathrm{ml}$ of the culture. These results are in agreement with Afzal and Muneer (1990); Tariq et al. (1997). During this study Brain Heart Infusion (BHI) broth was used for cultivation of $P$. multocida which is in accordance with Khan et al. (2013) who found that $\mathrm{BHI}$ is highly enriched media that supports $P$. multocida growth as compared to plain broth and nutrient broth.

According to Aucouturier et al. (2001) water in oil emulsions allows the reduction of the vaccine dose or the antigen concentration. During this study $2 \mathrm{mg}$ antigen was achieved in one $\mathrm{ml}$ and equal parts of Eolane adjuvants 
(Eolane-150 and Eoane-170) were mixed to formulate a single dose of $2 \mathrm{ml}$ vaccine per animal. Hence a reduction in dose was achieved (2 ml/animal) as compared to alum precipitated vaccine (5 ml/animal) which was previously used in the field to vaccinate the animals against HS disease in Punjab, Pakistan. Oil based vaccines adjuvanted with Eolane-150 and Eolane-170 adjuvant oils were stable upto 90 days at different temperatures such as $4^{\circ} \mathrm{C}$ and $25^{\circ} \mathrm{C}$ and these findings are in accordance with Aucouturier et al. (2001); Sotoodehnia et al. (2005). There was no change in colour, no liquefaction and no phase separation of the both vaccines upto 90 days at $4^{\circ} \mathrm{C}$ and $25^{\circ} \mathrm{C}$ as similar results have been observed by Bain et al. (1982); Koh et al. (2006); Kumar et al. (2015). Both vaccines were also found stable after performing centrifugation test upto 90 days and these results are in accordance with Koh et al. (2006); Kumar et al. (2015) who also observed similar results. The drop test was cleared for water in oil emulsion upto 90 days and our results also support the findings of Bain et al. (1982); Bomford (1997); Mowat et al. (1997) and Aucouturier et al. (2001).

Eolane-150 and Eolane-170 are new generation mineral oils used for oil adjuvanted vaccines world widely and complies the Food and Drug Administration (FDA) requirements of mineral oil. Furthermore, Eolane-170 meets the requirements of purity of United States Pharmacopeia and is in compliance with the general requirements of EU regulation (TOTAL FLUIDES, FRANCE). The vaccine prepared by Eolane is uniformly dispersed having micron size droplets, ensured maximum emulsion stability, decreased viscosity, easy to inject in animals, minimal or no undesirable side effects and is very highly cost effective. Sri Lanka and Indonesia have successfully used lower levels of lanoline as the emulsifying agent in an effort to reduce viscosity of oil adjuvanted HS vaccine. (Lubroth et al. 2007).

During the study, maximum protection was obtained with HS oil adjuvanted vaccines after challenge at 30 and 45 days post vaccination by $100 L_{50}$ and $1000 L_{50}$ in PMPT and a five log protection was obtained in AMPT. These results are in consonance with earlier findings that observed OAV as potent vaccine (Dutta et al., 1990; Chandrasekaran et al., 1994; Sotoodehnia et al., 2005). The results of IHA conducted on serum samples of two rabbit groups vaccinated with HS vaccine adjuvanted with Eolane-150 and Eolane-170 indicated that HS vaccine adjuvanted with Eolane-150 gave initially high level of antibodies titre (GMT=32) from $45^{\text {th }}$ day to $75^{\text {th }}$ day which later on declined $(G M T=16)$ upto 90 days post vaccination. The other group of rabbits vaccinated with HS vaccine adjuvanted with Eolane-170 gave constant protective antibodies titre $(\mathrm{GMT}=16)$ upto 90 days post vaccination (Figure 1) while the control group did not show any rise in GMT (Jaffri et al., 2006; Afrooz et al., 2016). Indirect Haem-Agglutination test and Passive Mouse Protection Test were used to calculate the potency of oil based vaccines as described by Nagarajan et al. (1972); Gupta and Sareen (1975); Chandrasekaran and Yeap (1978); Sotoodehnia et al. (2005); Jaffri et al. (2006). Both of these tests were also found satisfactory in evaluation of HS oil based vaccines prepared from Eolane-150 and Eolane-170 oil adjuvants. Passive Mouse Protection Test and Active Mouse Protection Test have been described as satisfactory for measuring immunity in either vaccinated or naturally immuned animals and survival of any mice in this test group identifies an immune serum, provided that all of an equal numbers of control mice die (Bain, 1963; Thomas, 1970; Sotoodehnia et al., 2005).

Properties like easy to inject with no side effects such as swelling at the injection site, longer protection against HS disease and cost effectiveness will hopefully motivate the livestock owners to use this new product to protect their animals against fatal HS disease. However, there is need for the evaluation of both vaccines in large animals like cattle and buffalo.

\section{CONCLUSION}

Oil adjuvant vaccines prepared from Eolane-150 and Eolane-170 are considered as potent vaccine against $\mathrm{HS}$ which will provide minimum one year protection, easy to inject, reduced dose rate, user friendly and no swelling/reaction at injection site.

\section{ACKNOWLEDGEMENTS}

The authors are highly grateful to Director, Veterinary Research Institute, Lahore for providing all laboratory facilities for executing the experimental work in the best interest of livestock industry. Authors are also thankful to Mr. Irfan Rashid, Manager Special Fluids, TOTAL PARCO, Pakistan for providing special assistance for this study. Authors are also grateful to Mr. Linus NG, Business Development Manager, TOTAL PARCO, Pakistan for reviewing this research study. 


\section{AUTHOR'S CONTRIBUTION \\ W. Shahzad: Intellectual \\ B. Zameer: Intellectual \\ S. Hussain: Intellectual \\ S. Hussain: Intellectual \\ N. Mustafa: Intellectual}

\section{REFERENCES}

Abbas, A. K., A. H. Lichtman and J. S. Pober. 1991. Cellular and Molecular Immunology, W.B. Saunders Company, London, UK, p. 417.

Afroz, H., S. Sattar, A. Rasool, B. Zamir, I. Haq and R. Rafique. 2016. Comparison of immunogenic effect of three oil adjuvant vaccines against Haemorrhagic Septicaemia in cattle and buffalo. International Archives of Bio-medical and Clinical Research, 2: 4348.

Afzal, M. and R. Muneer. 1990. Development of combined vaccine of Haemorrhagic Septicaemia and Foot and Mouth disease. Pakistan Veterinary Journal, 10 (2): 67-69.

Aguilar, J. C. and E. G. Rodriguez. 2007. Vaccine adjuvants revisited. Vaccine, 25 (19): 3752-3762.

Aucouturier, J., L. Dupuis and V. Ganne. 2001. Adjuvants designed for veterinary and human vaccines. Vaccine, 19 (17-19): 26662672.

Bain, R. V. S. 1963. Haemorrhagic Septicaemia. FAO Agricultural Studies No. 62. FAO, Rome, Italy.

Bain, R. V. S., M. C. L. De Alwis, G. R. Carter and B. K. Gupta. 1982. Haemorrhagic Septicaemia. FAO Publication, Rome, Italy.

Bomford, R. 1997. Adjuvants in veterinary vaccines. In: Vaccine Manual: The Production and Quality Control of Veterinary Vaccines for use in Developing Countries.FAO, Rome, Italy.

Bratbak, G. and I. Dundas.1984. Bacterial dry matter content and biomass estimations. Applied Environmental Microbiology, 48 (4): 755-757.

Chandrasekaran, S. and P. C. Yeap. 1978. Safety and potency testing of Haemorrhagic Septicaemia oil adjuvant vaccine by mouse protection test. Kajian Veterinaria, 10: 28-34.

Chandrasekaran, S., I. Kennett, P. C. Yeap, N. Muiandy, B. Rani and T. K. S. Mukkur. 1994. Characterization of immune response and duration of protection in buffaloes immunized with Haemorrhagic Septicaemia vaccines. Veterinary Microbiology, 41 (3): 213-219.
Dutta, J., B. Rathore, S. Mullick, R. Singh and G. Sharma.1990. Epidemiological studies on occurrence of Haemorrhagic Septicaemia in India. Indian Veterinary Journal, 67 (10): 893-899.

Farooq, U., Z. Saeed, M. A. Khan, I. Ali and M. F. Qamar. 2011. Sero-surveillance of Haemorrhagic Septicaemia in buffaloes and cattle in southern Punjab, Pakistan. Pakistan Veterinary Journal, 31 (3): 254-256.

Gupta, M. I. and R. I. Sareen. 1976. Evaluation of Haemorrhagic septicaemia oil adjuvant vaccine by the mouse protection test. Indian Veterinary Journal, 53 (7): 489-492.

Jabbari, A. R. and G. R. Moazeni Jula. 2004. Potency testing of modified alum adjuvant Haemorrhagic Septicaemia vaccine in laboratory and farm animals. Archives of Razi Institute, 57: 97-104.

Jaffri, K. T., Z. J. Gill, A. R. Bhatti and A. Raza. 2006. Immune response of buffalo calves to Haemorrhagic Septicaemia oil adjuvant and alum precipitated vaccine. International Journal of Agriculture and Biology, 8: 645647.

Khan, A., M. K. Saleemi, M. Z. Khan, S. T. Gul, M. Irfan and M. S. Qamar. 2011. Haemorrhagic Septicaemia in buffalo (Bubalus bubalis) calves under sub-tropical conditions in Pakistan. Pakistan Journal of Zoology, 43 (2): 295-302.

Khan, A., S. Munir, Q. Jamal, M. Anees, S. A. Shah, S. K. Sherwani, A. Basit, G. Ali, Asadullah and M. Hussain. 2013. Biomass production of Pasteurella multocida using biofermenter. International Journal of Advanced Research, 1 (5):142-151.

Koh, Y., S. Higgins, J. Weber and W. M. Kast. 2006. Immunological consequences of using three different clinical/laboratory techniques of emulsifying peptide-based vaccines in incomplete Freund's adjuvant. Journal of Transition Medicine, 4 (1): 42-42.

Kumar, S., V. K. Chaturvedi, B. Kumar, P. Kumar, S. R. Somarajan, A. K. Mishra and B. Sharma. 2015. Effect of alum coadjuvantation of oil adjuvant vaccine on emulsion stability and immune responses against Haemorrhagic Septicaemia in mice. Iranian Journal of Microbiology, 7 (2): 79-87.

Kumar, S., V. K. Chaturvedi, B. Kumar and P. Kumar. 2011. Immune response and viscosity of Haemorrhagic Septicaemia oil adjuvant vaccine at different water-oil proportion. Indian Journal of Animal Sciences, 81 (10): 1000-1004. 
Lubroth, J., M. M. Rweyemamu, G. Viljoen, A. Diallo, B. Dungu and W. Amanfu. 2007. Veterinary Vaccines and their use in developing countries. Revue Scientifiqueet Technique- Office International Des Epzooties, 26: 179-201.

Mowat, N and M. Rweyemamu. 1997. Vaccine Manual: The Production and Quality Control of Veterinary Vaccines for use in Developing Countries. FAO Animal Production and Health Series 35, Rome, Italy. p. 433.

Nagarajan, V., S. Sunderman and K. Ramandi. 1972. Evaluation of the potency of Haemorrhagic Septicaemia alum precipitated vaccine by mouse protection test. Indian Veterinary Journal, 49: 10801083.

OIE, 2018. Manual of Diagnostic Tests and Vaccines for Terrestrial Animals. Office De International Epizootics, Paris, France, pp. 732-745.

Reed, L. J. and H. Muench. 1938. A simple method of estimating 50 present endpoints. American Journal of Hygiene, 27 (3): 493497.
Shahzad, W., R. Munir, M. Asif, M. S. Sagar, M. Altaf, W. Aslam, G. Akbar and F. Mehmood. 2013. Prevalence, molecular diagnosis and treatment of field isolates of toxogenic Pasteurella multocida in a Haemorrhagic Septicaemia outbreak in Nili-Ravi Buffalo calves at Livestock Experiment Station, Bahadurnagar, Okara, Pakistan. Buffalo Bulletin, 32 (2): 1046-1050.

Sotoodehnia, A., G. Moazeni, S. Ataei and B. Omidi. 2005. Study on immunity of an experimental oil adjuvant Haemorrhagic Septicaemia vaccine in cattle. Archives of Razi Institute, 59 (2): 95-101.

Tariq, M. A., K. Muhammad, P. Das and M. A. Sheikh. 1997. Preparation and evaluation of alum precipitated and oil-based Haemorrhagic Septicaemia vaccines. Pakistan Veterinary Journal, 17 (4): 175178.

Thomas, J. 1970. Studies on HS oil adjuvant vaccine III Serological Studies. Kajian Veterinarise Veterinary Bulletin. Abstract, 1718.

(Received: July 02, 2019; Accepted: June 23, 2020) 